\title{
Longitudinal Hemodiafilter Performance in Modeled Continuous Renal Replacement Therapy
}

\author{
Deborah A. Pasko ${ }^{a, b}$ Mariann D. Churchwell ${ }^{b, c}$ Noha N. Salamab, d, e \\ Bruce A. Mueller ${ }^{a, b}$ \\ a Department of Clinical, Social and Administrative Sciences, University of Michigan College of Pharmacy, and \\ ${ }^{b}$ Renal Replacement Therapy Kinetics Study Group, Ann Arbor, Mich., 'Department of Pharmacy Practice, \\ University of Toledo College of Pharmacy, Toledo, Ohio, and d Division of Basic and Pharmaceutical Sciences,

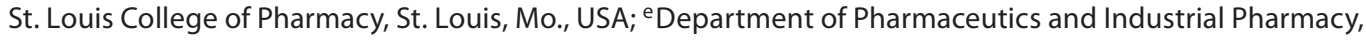 \\ Faculty of Pharmacy, Cairo University, Cairo, Egypt
}

\section{Key Words}

Clearance $\cdot$ Continuous renal replacement therapy •

Hemodialysis $\cdot$ Hemofiltration

\begin{abstract}
Background/Aims: With advanced anticoagulation, many institutions operate continuous renal replacement therapy (CRRT) circuits longer than manufacturers' recommendations. This extended use may change hemodiafilter performance and clearance properties. However, hemodiafilter performance over time has not been assessed. We investigated solute clearance over time in modeled CRRT. Methods: In vitro continuous hemofiltration $(\mathrm{CH})$ and continuous hemodialysis (CD) were operated for $48 \mathrm{~h}$ using AN69 polyacrylonitrile, cellulose triacetate, F70 polysulfone, and Optiflux F160NR polysulfone hemodiafilters with citrated bovine blood. Urea, creatinine, gentamicin, vancomycin, and albumin clearances were assessed in $\mathrm{CH}$ (ultrafiltration rates $=1$ and $3 \mathrm{I} / \mathrm{h}$ ). Clearances of urea, creatinine, gentamicin, and albumin, were assessed in CD with dialysate flow rate of 2 l/h. Results: Solute $\mathrm{CH}$ clearances were significantly higher at $3 \mathrm{l} / \mathrm{h}$. Only creatinine and gentamicin clearances were affected by time. Creatinine CD clearance significantly
\end{abstract}

\section{KARGER}

(C) 2011 S. Karger AG, Basel

Fax +41613061234 E-Mail karger@karger.ch www.karger.com www.karger.com/bpu declined at $48 \mathrm{~h}$ for all hemodiafilters, especially polysulfone hemodiafilters. Conclusions: CRRT duration affects solute transmembrane clearance. Clinicians should consider hemodiafilter age when assessing hemodialysis dose or drug clearance.

Copyright $\odot 2011$ S. Karger AG, Basel

\section{Introduction}

Continuous renal replacement therapy (CRRT) is a commonly employed treatment for critically ill patients with acute kidney injury. CRRT results in excellent volume control as well as effective electrolyte and metabolic control [1]. Solutes other than electrolytes and nitrogenous waste products are also removed during CRRT. Drugs, macro- and micronutrients, and cytokines are also cleared resulting in adjustments of drug [2-6] and nutrition regimens [7-9]. In fact, the use of CRRT [primarily continuous hemofiltration $(\mathrm{CH})]$ as an adjunctive treatment for septic shock [10-13] is largely a result of cytokine clearance.

When De Vriese et al. [13] studied cytokine removal in patients with septic shock by $\mathrm{CH}$, they noticed that the age

Bruce A. Muelle

University of Michigan College of Pharmacy

428 Church St.

Ann Arbor, MI 48109-1065 (USA)

Tel. +1 734763 6629, E-Mail muellerb@umich.edu 
of the hemodiafilter affected cytokine clearance. Cytokine clearance was highest when it was first used, and was considerably lower after $12 \mathrm{~h}$ of $\mathrm{CH}$. While these findings may be attributed to saturation of available cytokine binding sites on the hemodiafilter, they prompted us to consider the influence of hemodiafilter age on the transmembrane clearance of other solutes, namely drugs. Certainly, binding to hemodiafilter membranes does occur to some degree [14-16], but for most drugs, the primary method of drug clearance by CRRT is transmembrane clearance by convection and/or diffusion. As blood is exposed to the hemodiafilter, a proteinaceous secondary membrane is formed, possibly as soon as the first few minutes of CRRT [17]. The formation of a secondary membrane over the existing hemodiafilter membrane could hinder convective solute removal and reduce transmembrane clearance as the secondary membrane thickens.

In the early days of CRRT, heparin was the primary anticoagulant used and CRRT circuit duration was limited, usually because of hemodiafilter clotting. Early $\mathrm{CH}$ reports indicated that hemodiafilter life averaged approximately $24 \mathrm{~h}$ [18]. As $\mathrm{CH}$ technology improved, and citrate anticoagulation use increased, hemodiafilter and circuit life spans increased [19]. Hemodiafilter manufacturers often set a time limit for how long the hemodiafilter should be used before changing, typically $48-72 \mathrm{~h}$. However, with hemodiafilters clotting less frequently, many institutions have extended their routine circuit changing schedule in the spirit of cost containment. Hemodiafilters are now being used for as long as $96 \mathrm{~h}$ in many institutions, including our own. This 'extended' use of hemodiafilters may affect the convective and diffusive clearance capacity. Solute transmembrane clearance when a CRRT circuit is initiated may be quite different than what it is days later, but this question has not been addressed even within the first $48 \mathrm{~h}$ of hemodiafilter use. The purpose of these studies discussed herein was to assess transmembrane clearance at various time points with an in vitro $\mathrm{CH}$ and continuous hemodialysis (CD) model using 4 different hemodiafilters.

\section{Methods}

Our previously published in vitro models of CRRT were used for this trial $[3,4]$.

\section{Continuous Hemofiltration}

$\mathrm{CH}$ was accomplished using a B. Braun Diapact (Bethlehem, Pa., USA) machine that was primed with heparinized saline according to the manufacturer's instructions. Formed ultrafiltrate
Table 1. Study solutes: molecular weights and initial blood concentrations

\begin{tabular}{lcl}
\hline Solute & $\begin{array}{l}\text { Molecular } \\
\text { weight, Da }\end{array}$ & $\begin{array}{l}\text { Initial blood } \\
\text { concentration }\end{array}$ \\
\hline Urea & 60 & $75 \mathrm{mg} / \mathrm{dl}$ \\
Creatinine & 112 & $10 \mathrm{mg} / \mathrm{dl}$ \\
Gentamicin & 470 & $10 \mathrm{mg} / \mathrm{l}$ \\
Vancomycin & 1,448 & $50 \mathrm{mg} / \mathrm{l}$ \\
Bovine albumin & approx. 65,000 & $\begin{array}{c}3 \mathrm{~g} / \mathrm{dl} \text { (already present in } \\
\text { bovine blood at 3 g/dl) }\end{array}$ \\
& &
\end{tabular}

was recirculated back into the blood reservoir so that the volume of blood never changed for the duration of an experiment, and no solutes were lost due to transmembrane clearance. Four different hemodiafilter types were assessed in this study:

(1) M60 AN69 hemodiafilter (Gambro, Lakewood, Colo., USA), surface area $=0.6 \mathrm{~m}^{2}$

(2) CT190, cellulose triacetate (Baxter, Deerfield, Ill., USA), surface area $=1.9 \mathrm{~m}^{2}$

(3) F70, polysulfone (Fresenius, Waltham, Mass., USA), surface area $=1.7 \mathrm{~m}^{2}$

(4) O160, Optiflux F160NR, polysulfone, (Fresenius, Waltham, Mass., USA), surface area $=1.6 \mathrm{~m}^{2}$.

In a water bath, 1 liter of citrated bovine whole blood (Animal Technologies, Tyler, Tex., USA) was warmed to $37^{\circ} \mathrm{C}$ and continually stirred. A 'cocktail' of solutes was added to the blood reservoir so that their clearance could be assessed periodically (table 1).

Blood with the added solutes was allowed to flow through the circuit at $200 \mathrm{ml} / \mathrm{min}$ in bypass mode (no ultrafiltrate formed) for $20 \mathrm{~min}$ prior to starting the experiment to permit initial secondary membrane formation. After $20 \mathrm{~min}$ of blood recirculation, ultrafiltration was turned on and the experiment ran for $48 \mathrm{~h}$. Two different ultrafiltrate production rates were to be tested, 1 and $3 \mathrm{l} / \mathrm{h}$; however, an ultrafiltrate rate of $3 \mathrm{l} / \mathrm{h}$ could not be accomplished with the smaller M60 hemodiafilter. Consequently, the M60 was only tested at an ultrafiltration rate of 1 l/h. Five experiments were performed for each experimental condition, each with a new, nonreused hemodiafilter. Consequently, 35 total experiments were performed; 5 for each hemodiafilter (4 types) and ultrafiltration rate ( 1 and 3 l/h; except for the M60 which was only assessed at $1 \mathrm{l} / \mathrm{h})$.

Continuous Hemodialysis

$\mathrm{CD}$ was performed in a method similar to the $\mathrm{CH}$ model described above. The only differences were that calcium-free dialysate was run in a single-pass mode, countercurrently at a flow rate of $2 \mathrm{l} / \mathrm{h}$ with a blood flow rate of $200 \mathrm{ml} / \mathrm{min}$. The experiments were run so that the blood volume remained unchanged and no ultrafiltrate was formed. In the CD experiments, the CT190, F70, and Optiflux F160NR polysulfone were tested. The same solutes were tested in the blood with the exception of vancomycin, which was not included. 


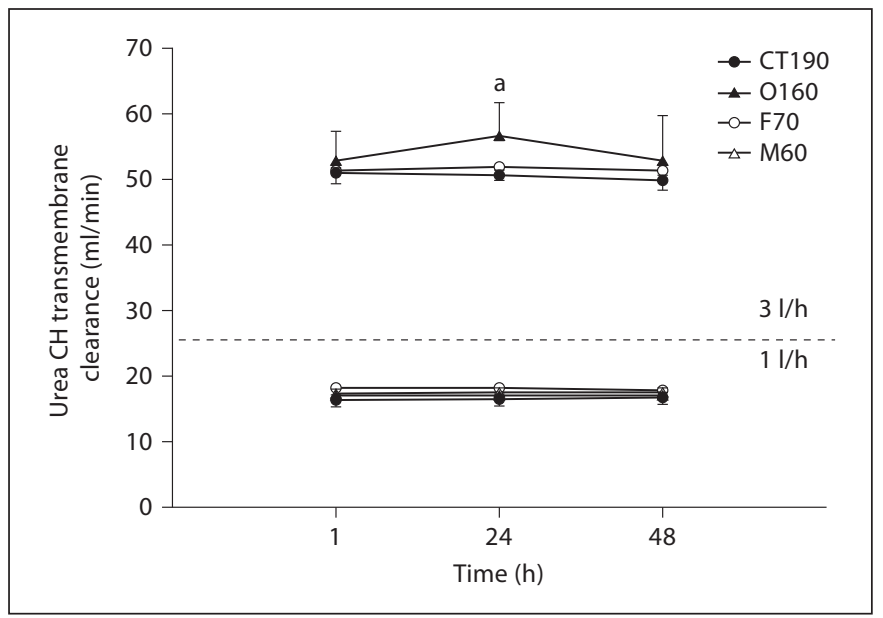

Fig. 1. Urea transmembrane convective clearance by $\mathrm{CH}$ at 1 and $31 /$ h. ${ }^{a}$ Significantly different from all hemodiafilters at the same time point $(\mathrm{p}<0.05)$.

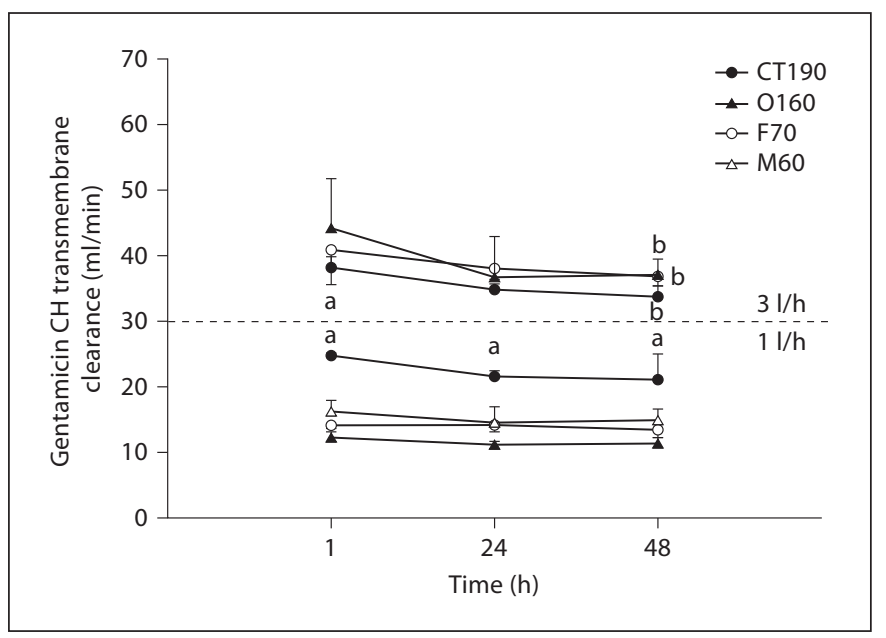

Fig. 3. Gentamicin transmembrane convective clearance by $\mathrm{CH}$ at 1 and $3 \mathrm{l} / \mathrm{h}$. ${ }^{\text {a }}$ Significantly different from all hemodiafilters at the same time point $(\mathrm{p}<0.05) ;{ }^{\mathrm{b}}$ significantly different from values detected at $1 \mathrm{~h}$ for the same hemodiafilter $(\mathrm{p}<0.05)$.

\section{Sampling}

Blood samples were obtained from the prefilter blood access port. Ultrafiltrate/dialysate samples were taken from the ultrafiltrate/dialysate access port simultaneous to the blood sampling. Samples were taken 1,24, and $48 \mathrm{~h}$ after $\mathrm{CH}$ or CD was instituted. Blood samples were allowed to clot and were then centrifuged and the plasma immediately extracted. Plasma and ultrafiltrate/dialysate samples were labeled properly, placed in cryovials, and immediately frozen at $-80^{\circ} \mathrm{C}$. All study solutes were assayed in batches using a COBAS Integra 400 Plus Auto analyzer (Roche Diagnostics, Indianapolis, Ind., USA).

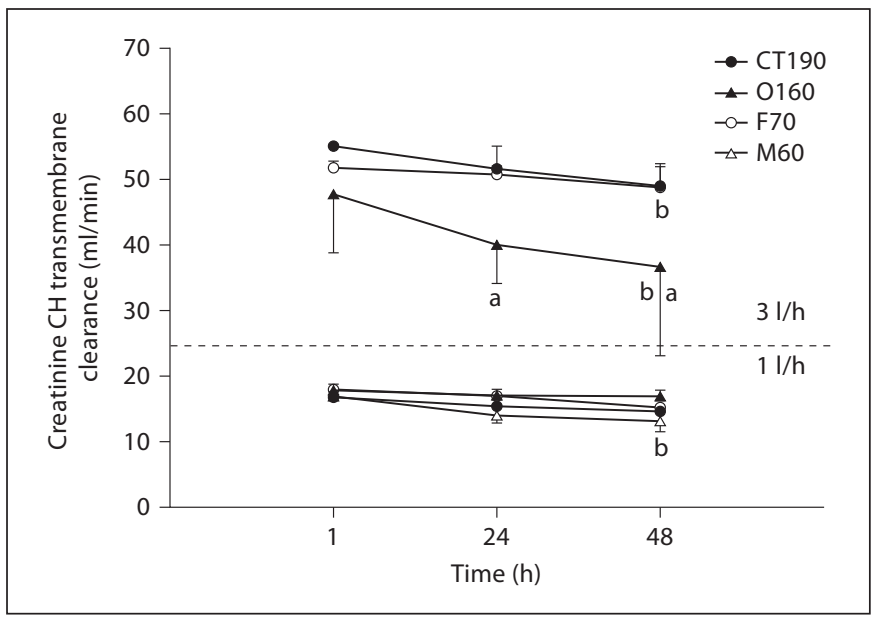

Fig. 2. Creatinine transmembrane convective clearance by $\mathrm{CH}$ at 1 and $31 /$ h. ${ }^{a}$ Significantly different from all hemodiafilters at the same time point $(\mathrm{p}<0.05) ;{ }^{\mathrm{b}}$ significantly different from values detected at $1 \mathrm{~h}$ for the same hemodiafilter $(\mathrm{p}<0.05)$.

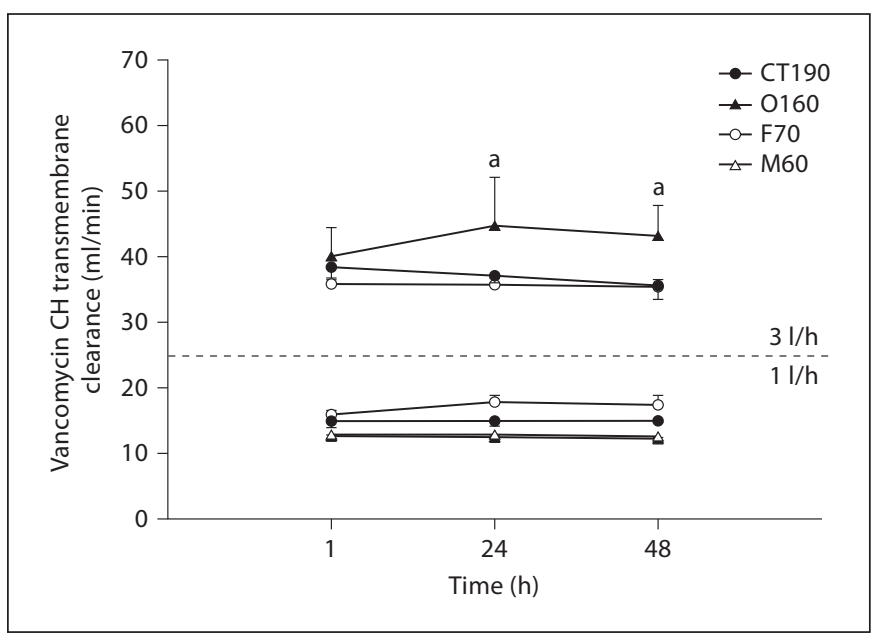

Fig. 4. Vancomycin transmembrane convective clearance by $\mathrm{CH}$

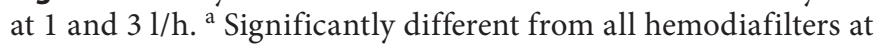
the same time point $(\mathrm{p}<0.05)$.

\section{Calculations}

Solute sieving coefficient (SC) was calculated at each time point by dividing the ultrafiltrate/dialysate solute concentration by the prefilter plasma concentration. Solute clearance was calculated by multiplying SC by ultrafiltrate/dialysate production rate.

\section{Statistical Analysis}

The statistical analysis for the experiments was assessed using a three-step analysis. First we fitted a linear mixed model, with hour as a 'fixed effect' and filter as a 'random effect'. This allows the correlation of observation for the same filter over time to be 


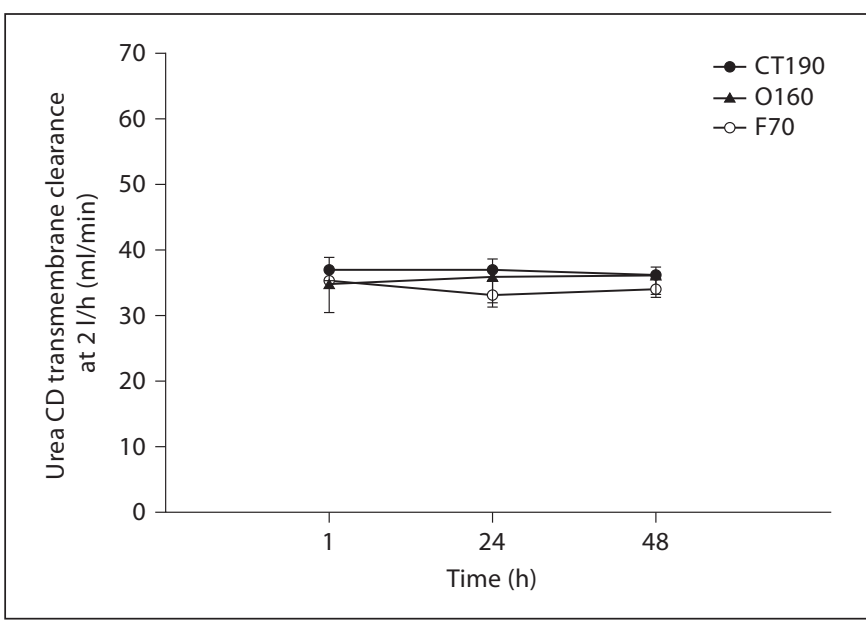

Fig. 5. Urea transmembrane dialytic clearance by CD at $21 / \mathrm{h}$.

taken into account appropriately, and it allows for and controls for variability between filters. Second, we also used a likelihood ratio $\chi^{2}$ test to examine the significance of the random variability between filters. Finally a post hoc comparison of the means for each time point was carried out using the Tukey-Kramer adjustment for multiple comparisons. Any measurement with a p value of 0.05 or less was considered to be statistically significant.

\section{Results}

All CH and CD circuits survived to $48 \mathrm{~h}$ at each of the filter and ultrafiltrate/dialysate combinations tested. Mean SC and resultant clearance rates varied by filter and solute, with the exception of albumin which exhibited a $\mathrm{SC}$ ranging from 0.02 to below the detection limit of the assay.

\section{Continuous Hemofiltration}

In general, solute clearances were significantly higher when an ultrafiltration rate of $3 \mathrm{l} / \mathrm{h}$ was used compared to 1 l/h. Figures 1-4 illustrate a general trend showing a decline in clearance from initial values at $3 \mathrm{l} / \mathrm{h}$. In no case did any solute show a statistically significant increase in clearance from 1 to $48 \mathrm{~h}$. Creatinine transmembrane clearance across the M60 hemodiafilter declined significantly from 1 to $48 \mathrm{~h}$ with a 1 l/h ultrafiltration rate $(\mathrm{p}<$ 0.05). At an ultrafiltration rate of $3 \mathrm{l} / \mathrm{h}$, the creatinine transmembrane clearance declined significantly from 1 to $48 \mathrm{~h}$ with the $\mathrm{O} 160$ ( $\mathrm{p}<0.001)$ and CT190 ( $\mathrm{p}<0.05)$ hemodiafilters.

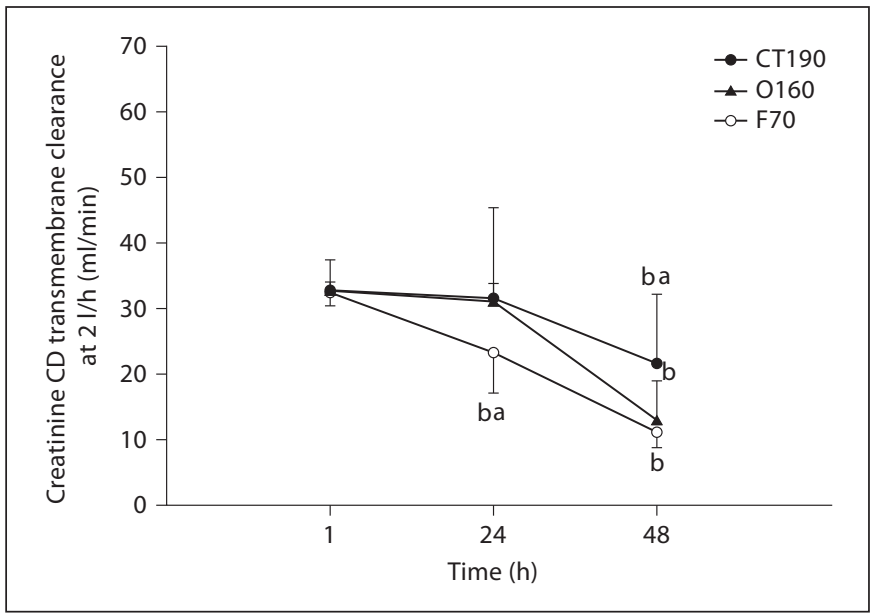

Fig. 6. Creatinine transmembrane dialytic clearance by $\mathrm{CD}$ at $2 \mathrm{l} / \mathrm{h}$. ${ }^{\text {a }}$ Significantly different from all hemodiafilters at the same time point $(\mathrm{p}<0.05)$; ${ }^{\mathrm{b}}$ significantly different from values detected at $1 \mathrm{~h}$ for the same hemodiafilter $(\mathrm{p}<0.05)$.

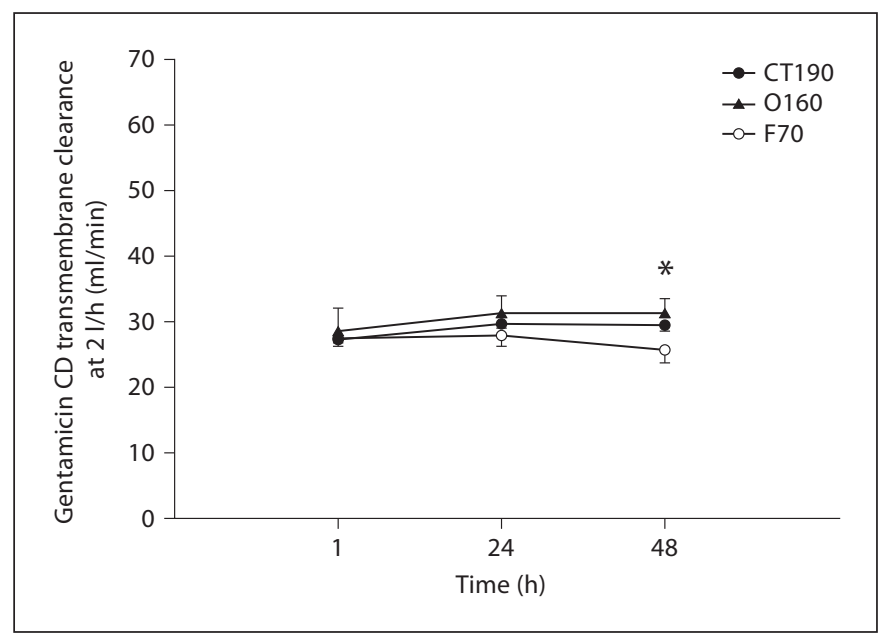

Fig. 7. Gentamicin transmembrane dialytic clearance by $C D$ at 2 1/h. ${ }^{*} \mathrm{p}<0.05$ : significantly different from values detected at $1 \mathrm{~h}$ for the same hemodiafilter.

All hemodiafilters showed a significant decline in gentamicin transmembrane clearance from 1 to $48 \mathrm{~h}$ at $3 \mathrm{l} / \mathrm{h}$ of $\mathrm{CH}(\mathrm{F} 70=0.05, \mathrm{O} 160 \leq 0.0005, \mathrm{CT} 190<0.05)$. No significant differences in clearance over time were noted for urea or vancomycin. Differences in solute clearances between filter types were noted for the 4 solutes at all 3 time points assessed. In general, the M60 hemodiafilter tended to have the lowest solute clearance; however, no generalizations beyond this observation could be made.

Blood Purif 2011;32:82-88 


\section{Continuous Hemodialysis}

Figures 5-7 show solute clearances for each of the 3 tested hemodiafilters. No significant changes occurred over time or between filters for urea (fig. 5). Creatinine transmembrane clearance declined significantly for all 3 filters from 1 to $48 \mathrm{~h}$ (fig. 6). The decline in creatinine clearance was most profound with the polysulfone hemodiafilters (F70, O160) compared to the cellulose triacetate hemodiafilter (CT190) from 1 to $48 \mathrm{~h}(\mathrm{p}<0.001)$. Gentamicin clearances did not differ significantly between hemodiafilters but transmembrane clearance for the polysulfone hemodiafilter O160 increased slightly from 1 to $48 \mathrm{~h}(\mathrm{p}<0.05)$.

\section{Discussion}

This study assesses the influence of time on solute clearance in CRRT in vitro models. Multiple solutes were added to citrated whole bovine blood and samples were obtained from the prefilter blood access port. We found that solute transmembrane clearance declined with time, particularly for creatinine, and in the case of $\mathrm{CH}$, gentamicin. This was more apparent at the higher $\mathrm{CH}$ flow rates of $31 / \mathrm{h}$, suggesting that membrane factors such as protein layering and clogging may be more significant at higher ultrafiltration rates.

The issue of hemodiafilter performance over time is one that has not received much scrutiny, possibly because it is difficult to assess and may be dependent on which solute clearance is measured. In practice, urea clearance is used to describe hemodialyzer performance in hemodiafilter manufacturer package inserts and is the gold standard for dialysis adequacy $\left(\mathrm{KT} / \mathrm{V}_{\text {urea }}\right)$ calculations. Clinicians frequently use urea clearance as a surrogate marker of hemodiafilter performance to determine if the hemodiafilter needs to be changed. Literature and clinical support suggests the use of a ratio known as FUN/BUN, or the ratio of ultrafiltration fluid urea nitrogen to blood urea nitrogen [20,21]. Similarly, an analogous dialysate urea nitrogen (DUN)/BUN ratio could be used for CD. Over a decade ago, Mehta and Martin [22] suggested that FUN/BUN be assessed every $12 \mathrm{~h}$ to determine hemodiafilter performance. Our own institution measures DUN/BUN daily in patients receiving CRRT. Some have suggested that the hemodiafilter should be changed when FUN/BUN decreases by 20 $40 \%$ [20-22].

At no point in the present trial was a $20 \%$ decline in FUN/BUN or DUN/BUN observed, even after $48 \mathrm{~h}$ of therapy. Consequently, if this were a clinical situation using this $>20 \%$ rule of thumb, we would not have changed our hemodiafilter circuit. However, in many of our circuits with 'normal' FUN/BUN ratios, significant decrements in creatinine and gentamicin transmembrane clearances were occurring. Even though FUN/BUN was never affected, the decrease in $\mathrm{CH}$ gentamicin transmembrane clearance seen within $48 \mathrm{~h}$ could translate to changes in drug dosing at the bedside. In the present study, gentamicin transmembrane clearance declined by $11.7 \%$ for the CT190, 16\% for the O160, and approximately $28 \%$ for the F70 from 1 to $48 \mathrm{~h}$. Clearance change of this magnitude could be clinically significant and may necessitate substantial changes to the gentamicin dosing regimen. An advantage of any CRRT is that continual drug clearance will result in a near-steady-state condition, similar to what is seen in patients with unchanging endogenous renal function. Dependent on when the gentamicin was dosed in the life span of the hemodiafilter, an $11.7-28 \%$ change in gentamicin clearance would certainly complicate gentamicin dosing. Gentamicin pharmacokinetic monitoring done when a hemodiafilter is new would result in higher serum concentrations as the hemodiafilter ages. In contrast, gentamicin pharmacokinetic monitoring done when a hemodiafilter is old could result in substantial underdosing when an old filter is exchanged with a new one. Many centers use hemodiafilters for 72-96 h. If the trend in gentamicin clearance reduction continues beyond the $48 \mathrm{~h}$ that we studied, the implications of these clearance swings could even be more profound. Similarly, over the $48 \mathrm{~h}$ of all the CRRT filter and flow rate combinations, creatinine transmembrane clearance declined from $4.6 \%(1 \mathrm{l} / \mathrm{h}, \mathrm{O} 160$ filter, $\mathrm{CH})$ to $66.1 \%$ (2 1/h, F70 filter, CD). Obviously, a clearance reduction of this magnitude could result in a substantial increase in serum creatinine. These serum creatinine increases would be unanticipated by caretakers and could further complicate management of these patients, primarily because it is unlikely that physicians would consider reduced hemodiafilter performance as the causative factor.

The concept of using a sensitive, readily available marker to predict when a hemodiafilter needs to be changed is attractive. However, by the time a hemodiafilter is so clogged that the clearance of a 60 -dalton nonprotein-bound molecule (urea) is hindered by $>20 \%$, the clearance of larger solutes may have already been impaired much earlier in the CRRT circuit life span. Our results suggest that reductions in creatinine and gentamicin transmembrane clearance occur well before any 
change in urea clearance occurs. This calls into question the clinical utility of FUN/BUN (or DUN/BUN in the case of $\mathrm{CD}$ ). Ultrafiltrate creatinine/serum creatinine might prove to be a better marker than FUN/BUN, as changes in ultrafiltrate creatinine/serum creatinine occurred within $24-48 \mathrm{~h}$ in our experiments. Whether ultrafiltrate creatinine/serum creatinine would be a predictive marker of overall hemodiafilter performance has yet to be studied. Creatinine is also a relatively small solute $(112 \mathrm{Da})$ and its clearance may not be representative of overall filter performance.

Because each of these solutes appeared to be affected differently by CRRT duration with each hemodiafilter and CRRT modality, it seems that trying to simplify hemodiafilter performance to a single ratio (i.e. FUN/BUN) may not be as useful as first thought. Indeed, initial recommendations for FUN/BUN monitoring were made in the early to mid-1990s $[20,22]$ when CRRT machines were rather rudimentary. Contemporary CRRT machines now continually monitor arterial, venous, ultrafiltrate/dialysate and transmembrane pressures within the circuit. It is likely that some of these measures are better predictors of membrane performance and impending circuit failure.

These results may have a bearing when considering issues like actual delivered dose of dialysis, which is often assumed from the time that CRRT is running, or from volume of ultrafiltrate/dialysate produced per unit time. Indeed, a decreased efficiency of urea removal by CRRT has recently been identified as a more significant contributor to a decrease in the delivered dose of CRRT than was CRRT circuit downtime [23]. Actual delivered dose of solute clearance no doubt differs by solute, but, as shown in the present study, may also differ with CRRT duration. If this is true, then these concepts should be considered when interpreting studies that have attempted to compare patient outcome with a particular dose of CRRT as well as pharmacokinetic trials that assess CRRT drug clearance. Changes in actual solute/drug clearance over time may influence interpretations of these studies, and in the case of drugs, may result in the potential for differences in drug dosages.

\section{Limitations}

One of the limitations of our in vitro study design is that we did not assess the extent of specific solute adsorption nor did we collect postfilter samples. Prior to the experiment, we expected that the largest solutes would show a decrease in clearance over time earlier and to a greater extent than would urea. Our reasoning was that the larg- er solute's transit through hemodiafilter pores would be most sensitive to a narrowing in pore size that might be seen as a hemodiafilter clogs. Consequently, we should have seen the biggest changes in vancomycin transmembrane clearance in this experiment, but we did not. Changes in clearances were far more evident for gentamicin and creatinine than for vancomycin. Whether this has to do with some physicochemical property of vancomycin compared to the other tested solutes or some other reason is unclear. Uchino et al. [24] reported that 'protein fouling' in high-volume hemofiltration $(6 \mathrm{l} / \mathrm{h})$ might reduce vancomycin $\mathrm{SC}$ with $\mathrm{CH}$ duration. We did not perform $\mathrm{CH}$ at $6 \mathrm{l} / \mathrm{h}$, and did not find evidence of substantial vancomycin SC decline after $48 \mathrm{~h}$ of $\mathrm{CH}$ conducted at 1 and $31 / h$

\section{Conclusion}

The transmembrane clearance of most solutes in CRRT is likely influenced by duration of therapy. Our data suggest that while urea clearance is maintained for $48 \mathrm{~h}$ of modeled therapy, the clearance of other solutes may be altered. More sensitive markers need to be determined to assess changes in hemodiafilter performance. These data need to be validated in clinical trials.

\section{Acknowledgments}

Dr. Noha N. Salama was supported by grant No. UL1RR024986 from the National Center for Research Resources (NCRR). The content is solely the responsibility of the authors and does not necessarily represent the official views of the NCRR or the National Institutes of Health. The authors would like to thank Kathleen B. Welch at the Center for Statistical Consultation and Research (CSCAR) at the University of Michigan for her assistance with statistical analysis. These studies were funded by National Kidney Foundation of Michigan (Ann Arbor, Mich., USA), the American College of Clinical Pharmacy (Lenexa, Kans., USA) and University of Michigan College of Pharmacy (Ann Arbor, Mich., USA) Clinical Research Resource grants.

\section{Disclosure Statement}

The authors claim no conflict of interest. 


\section{References}

-1 Clark WR, Mueller BA, Alaka KJ, Macias WL: A comparison of metabolic control by continuous and intermittent therapies in acute renal failure. J Am Soc Nephrol 1994; 4:1413-1420.

2 Mueller BA, Pasko DA, Sowinski KM: Higher renal replacement therapy dose delivery influences on drug therapy. Artif Organs 2003;27:808-814.

-3 Stevenson JM, Patel JH, Churchwell MD, Vilay AM, DePestel DD, Sörgel F, Kinzig M, Jakob V, Mueller BA: Ertapenem clearance during modeled continuous renal replacement therapy. Int J Artif Organs 2008:10271034.

4 Churchwell MD, Pasko DA, Mueller BA: Daptomycin clearance during modeled continuous renal replacement therapy. Blood Purif 2006;24:548-554.

$\checkmark 5$ Schetz M: Drug dosing in continuous renal replacement therapy: general rules. Curr Opin Crit Care 2007;13:645-651.

6 Aronoff GR, Bennett WM, Berns JS, Brier ME, Kasbekar N, Mueller BA, Pasko DA, Smoyer WE (eds): Drug Prescribing in Renal Failure: Dosing Guidelines for Adults and Children, ed 5. Philadelphia, American College of Physicians, 2007.

$\checkmark 7$ Churchwell MD, Pasko DA, Btaiche IF, Jain JC, Mueller BA: Trace element removal during in vitro and in vivo continuous haemodialysis. Nephrol Dial Transplant 2008;22: 2970-2977.

8 Macias WL, Alaka KJ, Murphy MH, Miller ME, Clark WR, Mueller BA: Impact of the nutritional regimen on protein catabolism and nitrogen balance in patients with acute renal failure. J Parenteral Enteral Nutr 1996; 20:56-62.
-9 Maxvold NJ, Smoyer WE, Custer JR, Bunchman TE: Amino acid loss and nitrogen balance in critically ill children with acute renal failure: a prospective comparison between classic hemofiltration and hemofiltration with dialysis. Crit Care Med 2000;28:11611165.

10 Rogiers P: Hemofiltration treatment of sepsis: is it time for controlled trials? Kidney Int 1999;72:S99-S103.

11 Bottoms G, Fessler J, Murphey E, Johnson M, Latshaw H, Mueller B, Clark W, Macias W: Efficacy of convective removal of plasma mediators of endotoxic shock by continuous veno-venous hemofiltration. Shock 1996;5: 149-154.

12 Bellomo R, Tipping P, Boyce N: Continuous veno-venous hemofiltration with dialysis removes cytokines from the circulation of septic patients. Crit Care Med 1993;4:522-526.

13 De Vriese AS, Colardyn FA, Philippe JJ, Vanholder RC, De Sutter JH, Lamiere NH: Cytokine removal during continuous hemofiltration in septic patients. J Am Soc Nephrol 1999;10:846-853.

14 Tian Q, Gomersall CD, Ip M, Tan TE, Joynt GM, Choi G: Adsorption of amikacin, a significant mechanism of elimination by hemofiltration. Antimicrob Agent Chemother 2008;53:1009-1013.

15 Choi G, Gomersall CD, Lipman J, Wong A Joynt GM, Leung P, Ramsay SJ, Ho OM: The effect of adsorption, filter material and point of dilution on antibiotic elimination by haemofiltration. An in vitro study of levofloxacin. Int J Antimicrob Agents 2004;24:468472 .
16 Tian Q, Gomersall CD, Leung PN, Choi G, Joynt GM, Tan PE, Wong A: The adsorption of vancomycin by polyacrylonitrile, polyamide, and polysulfone hemofilters. Artif Organs 2008;32:81-84.

17 Clark WR, Macias WL, Molitoris BA, Wang $\mathrm{NH}$ : Plasma protein adsorption to highly permeable hemodialysis membranes. Kidney Int 1995;48:481-485.

18 Martin PY, Chevrolet JC, Suter P, Favre H: Anticoagulation in patients treated by continuous venovenous hemofiltration: a retrospective study. Am J Kidney Dis 1994;24: 806-812.

19 Swartz R, Pasko DA, O’Toole J, Starmann B: Improving the delivery of continuous renal replacement therapy using regional citrate anticoagulation. Clin Nephrol 2004;61:134143.

20 Sigler MH, Manns M: Membranes and devices used in continuous renal replacement. Semin Dial 1996;9:98-106.

21 Marshall MR: Current status of dosing and quantification of acute renal replacement therapy. 2. Dosing paradigms and clinical implementation. Nephrol Dial Transplant 2006;11:181-191.

22 Mehta RL, Martin RK: Initiating and implementing a continuous renal replacement therapy program. Semin Dial 1996;9:80-87.

23 Wei J, Granado RC, Malhotra R, Macedo E, Luo Y, Soroko S, Mehta RL: The impact of down-time and filter efficacy on delivered dose of continuous renal replacement therapy. J Am Soc Nephrol 2010;21:38A.

24 Uchino S, Cole L, Morimatsu H, Goldsmith D, Bellow R: Clearance of vancomycin during high-volume haemofiltration: impact of pre-dilution. Intens Care Med 2002;28: 1664-1667. 